\title{
Simplistic is the Ingredient for Mobile Learning
}

\author{
doi:10.3991/ijim.v4i3.1159 \\ Issham Ismail, Hanysah Baharum and Rozhan M. Idrus \\ Universiti Sains Malaysia, Penang, Malaysia
}

\begin{abstract}
This study explored the students' acceptance of Mobile Learning via Short Message Service (SMS-Learning) amongst distance learners in the Universiti Sains Malaysia. This study aims to examine the student's acceptance towards the language use in SMS-Learning content, the cost of communicating and also the navigation of the system. The study employed the qualitative methodology where data were collected through questionnaire that was administered to 105 distance education students from Bachelor of Management, Bachelor of Science, Bachelor of Social Science and Bachelor of Art. The survey responses were tabulated in a 5-point Likert scale and analyzed using the Rasch Measurement Model. The results indicated that the simple language used in SMS-Learning was accepted by the respondents. By using the language precisely, it leads to high usability of SMS-Learning which will allow it to academically assist them in their study.
\end{abstract}

Index Terms-Mobile learning, Rasch model, SMS, text message

\section{INTRODUCTION}

The extension of mobile wireless technologies has contributed to the shifting of the educational environment from the traditional setting to an e-learning setting. In traditional education, both teachers and students are physically present together [1]. There are increasing numbers of higher institutions that offer courses using mobile devices as an alternative teaching and learning tools [2]. Mlearning or mobile learning is the type of learning characterized by the usage of wireless technology, through the personal control of the learning time and place [3]. SMS or text messaging is the transmission of short text messages to and from a mobile wireless phone, fax machine, and/or IP address.

The rapid evolution of mobile devices and quick development of wireless communication has paved the way for another alternative medium for higher education institution to employ mobile learning as a means to facilitate educational transaction to the learners. Mobile wireless technologies help to improve efficiency and effectiveness in teaching and learning with the advantages of mobility [4]. Mobile learning has been perceived by many educationalists to offer flexibility in learning and present a multitude yet unique educational advantages [5]. Regardless of such interests in mobile wireless technologies in higher education, there is lack of academic research on the use of mobile wireless technologies in the higher education setting [2].

A study done by Malaysian Communications and Multimedia Commission (MCMC) found that in Quarter 2, 2009 , the penetration rate for cellular phone in Malaysia is $100.8 \%$. Penetration rate over $100 \%$ occurs because of multiple subscriptions [6]. The mobile phone is a multi- purpose device and not only used for transmitting voice communication but at the same time also provides a number of other functions and services, such as the short messages service. Majority of mobile phone user used SMS as a communication tool for sending and receiving messages [7]. Nevertheless, there are an increasing number of SMS commercial services such as voting, news and sports alert, ringtones/logos and advertisements. The explosive growth of SMS usage can aid marketers in developing appropriate m-commerce services [8].

In this study, lecturers and students send and receive text messages to and from most high-tech mobile wireless phones through SMS. With SMS, messages are produced on the tiny keypad of the phone and users are able to exchange alphanumeric message (up to 160 characters) with other users of digital cellular networks, almost anywhere in the world within second of submission [9][10]. The use of SMS will potentially be increased in the education field as technology improves [11]. In order to have an effective SMS communication, both sender and receiver must understand the message that is delivered to them [12]. Thus, the language used in authoring the message has to be clear and understandable. SMS language is more like speaking than writing and more short-lived than letters. There are also unique formulations in SMS that have a slight foundation in writing and/or spoken language, but seem to be distinctive [12].

In order to evaluate the acceptance of SMS-Learning among students of distance education, satisfaction of the students on SMS-Learning will be considered. Wang developed a comprehensive model and instrument for measuring learners' satisfaction with asynchronous e-learning systems; and he found that satisfaction could be classified into the four following dimensions; content, personalization, learning community and learner interface [13]. Evaluation on learners' satisfaction of the web-based elearning system was the continuity of the previous research done which indicates that learner interface as being the most important dimension of criteria [14]. In the field of human-computer interaction, users satisfaction is the "subjective sum of interactive experiences" influenced by many affective mechanism in the interaction [15]. The interaction between instructors and learners play an important role in learning activities. Instructor's attitude towards e-Learning has significant effect on e-Learner's satisfaction where learning activities and learner's satisfaction are influenced by instructor's attitudes in handling learning activities [16].

In addition to this study, the usability of the system used is also to be considered. The concept of usability refers to the intention of using a computer system. Nowadays it is usually associated to ease-of-use of a website and is considered a critical factor on the development of electronic commerce [17]. Usability concerns the ease in 
which the user is capable of learning how to manage the system, the ease of memorizing the basic functions, the grade of efficiency with which the site has been designed, the degree of error avoidance and the general satisfaction of the users in terms of manageability[18]. Thus, website usability is defined as "a quality attribute that assesses how easy user interfaces are to use" [19]. Hence, this study proposes that the satisfaction towards using SMSLearning and the usability of the system contribute to the students' acceptance of the SMS-Learning project.

\section{METHOD}

\section{A. Participants}

In this study, the distance learners were given the opportunity to register and become a respondent in an SMSLearning programme. The samples for this study were selected by lecturers at the beginning of the semester. This SMS-Learning programme was conducted for 3 months commencing from February 2009 till the end of April 2009 (10 weeks). One hundred-five undergraduate students consisting of 31 males and 74 females had enrolled from four different programs (Bachelors of Science, Bachelor of Arts, Bachelor of Management and Bachelor of Social Science) in the School of Distance Education (SDE), Universiti Sains Malaysia (USM).

TABLE I.

COURSES OFFERED IN SMS-LEARNING PROGRAMME

\begin{tabular}{|l|l|c|}
\hline \multicolumn{1}{|c|}{ Programme } & \multicolumn{1}{|c|}{ Course } & Year of study \\
\hline Management & Financial Principle & 2 \\
& International Business & 3 \\
\hline Physics & Mechanics & 2 \\
& Optics & 2 \\
\hline Economics & Money and Banking & 2 \\
& Quantitative Economy & 3 \\
\hline
\end{tabular}

The learning materials given to these six groups of students were based on their courses taken. Each group was monitored by their own course manager. The SMSLearning materials for the courses were prepared by the respective course managers. All of the respondents declared that they are mobile phone owners and were able to participate in SMS-Learning Program.

\section{B. Instruments}

This study was conducted using a questionnaire-based survey that consisted of respondents' demographics, respondent's satisfaction towards SMS-Learning program and also the usability of SMS-Learning. The survey utilized a 5-point Likert-type scale that allows students to rate their agreement of each item of the survey. In this study, respondents were asked to rate the items correspond to a Likert-type rating scale where $1=$ strongly disagree, $2=$ disagree, $3=$ neutral, $4=$ agree, $5=$ strongly agree.

\section{Data Analysis}

The student's acceptance towards the language used in SMS-Learning Program, the cost of communicating and the navigation in the system are highlighted in this study. Data was entered for each respondent into WINSTEPS Version 3.68 employing the rating scale Rasch Model [20]. Rasch is mathematically identical to the most Item Response Theory (IRT) model; however it is compara- tively more viable proposition for practical testing since it can be applied in the context in which persons interacts with items [21].

When applying the Rasch model, data must fit the model, with the assumption of unidimensional domain being measured. In order to evaluate and analyze student's acceptance towards SMS-Learning program, several tables and figures are used in this study. A statistical summary table was produced to describe the separation rate and reliability of the persons and items. Separation is a number of statistically different performance strata that the test can identify in the sample. The reliability rate indicates whether the test discriminates the sample into enough levels for the intended measure [21].

Item and person misfit table was presented and explained. The statistics show how well the data fits the model, with fit implying a meeting of requirement or matching of intentions [21]. Basically, it was an investigation of the match between a group of persons and a set of items, specific to the intent of the measure. The empirical hierarchy of items was illustrated using variable map and connected to the students' level of ability to endorse each item, with each reported in logits. A logit (log-odds unit) is a unit of interval measurement which is well-defined within the context of a single homogenous test [22]. The variable map visually reveals the hierarchy and the order of the items as well as any potential gaps in measure [21].

\section{RESULTS AND DisCUSSION}

\section{A. Demographic profile of respondents}

This section portrays respondent's background such as gender, age, ethnicity, degree program and also type of mobile devices owned. As shown in table II, the number of females responding to the questionnaire slightly outnumbered males with $70 \%$ of females and $30 \%$ males ranging in age from 20 to above-50. It was noted that this age group prefer to pursue their studies in distance education because they remain in full time employment. As for ethnic structure, almost half of the respondents were Malay which is $57 \%$, while $26 \%$ were Chinese, $10 \%$ were Indian and $7 \%$ were from other ethnic group.

About $95 \%$ of the respondents were from Management program, 2\% for both Science and Social Science program and only $1 \%$ from Art program. From a total of 105 respondents in this survey, about $91 \%$ of them owned a mobile phone and 3\% have PDA/pocket PC/Palmtop. While $6 \%$ have both of mobile phone and PDA/pocket PC/Palmtop. The result shows that all of them declared that they have owned mobile phone and able to use SMSLearning program.

\section{B. Item and Person Misfit Order Table}

In order to identify item maps, fit statistic were examined to determine whether the item fits the maps or not. The person and item misfit is helpful when evaluating the acceptance of SMS-Learning program amongst students. The data must fit the model and meeting of requirements or matching a group of persons and items [21].

Table III shows the item statistics in a fit-order table produced by Winsteps. The results demonstrate whether the instrument functions as valid tools for data collection. Outfit mean-square fit statistics (MNSQs) are equivalent to a chi-square statistics; values greater than 2.0 indicate unexplained randomness throughout the data [23]. The 
item that fall within the infit and outfit limits of 0.6 and 1.5 were accepted in his analysis [24].

In this study analysis, the results demonstrate the outfit mean-square fit statistics (MNSQ $\leq 0.6 \geq 1.5$ ) for 13 items were acceptable to the model while 9 items fall outside the indicated range, suggesting either are not supporting the underlying construct or items need revamped, likely because respondent are viewing the items differently than that intended by the researcher.

\section{Reliability and Separation}

In order to have an overall view of the reliability and validity of the instruments and associated responses, the statistical summary tables of the persons and items were produced.

Reliability is the degree to which measures are free from error and therefore yield consistent results. The closer the reliability coefficient (Cronbach's Alpha) to 1.0 the better it is and those values over 0.80 are consider as good [25]. Values in 0.70 are acceptable while less than 0.60 considered as poor. In the reliability analysis, the alpha value that is closer the reliability coefficient to 1.00 is the better. In this study, the Cronbach's Alpha of 0.88 can be considered good.

Person reliability was 0.85 , with a separation of 2.37 . Item reliability was 0.90 , with a separation of 2.99 . Given a 0.7 threshold of acceptability, both scales are deemed reliable and usable for the purpose of this study. The person separation of 2.37 means students were roughly separated into 3 groups, later labeled as those who satisfied with the program, those who were fine with the program and those who dissatisfied with the program. For item separation of 2.99 , it indicated 13 items a generally separated into 3 groups. Label as items that students satisfied, items that students thought were fine and items that students unsatisfied. The person reliability of 0.85 is good for the sample of 105 . The item reliability is 0.90 which is reasonably high considering sample size and small numbers of items. Thus, the survey as a whole appears to have functional reliability.

TABLE II.

DEMOGRAPHIC DATA

\begin{tabular}{|l|c|c|}
\hline \multicolumn{1}{|c|}{ Item } & Frequency & Per cent \\
\hline Gender & & \\
Male & 31 & 30 \\
Female & 74 & 70 \\
\hline Age & & \\
20-29 years & 44 & 42 \\
30-39 years & 46 & 44 \\
40-49 years & 12 & 11 \\
50 and above & 3 & 3 \\
\hline Ethnicity & & \\
Malay & 60 & 57 \\
Chinese & 11 & 10 \\
Indian & 27 & 26 \\
Others & 7 & 7 \\
\hline Program & & \\
B. Science & 2 & 2 \\
B. Arts & 1 & 1 \\
B. Social Science & 2 & 2 \\
B. Management & 98 & 95 \\
\hline Mobile Device Ownership & & \\
Mobile phone & 96 & 91 \\
Both & 6 & 6 \\
PDA/Pocket PC/Palmtop & 3 & 3 \\
\hline
\end{tabular}

TABLE III.

FIT STATISTICS FOR STUDENTS' SATISFACTION AND SYSTEM USABILITY

\begin{tabular}{|c|c|l|c|c|}
\hline No & Item & \multicolumn{1}{|c|}{ Statement } & $\begin{array}{c}\text { Infit } \\
\text { MNSQ }\end{array}$ & $\begin{array}{c}\text { Outfit } \\
\text { MNSQ }\end{array}$ \\
\hline 1 & USE140 & $\begin{array}{l}\text { The language used is simple } \\
\text { enough. }\end{array}$ & 0.88 & 0.81 \\
\hline 2 & SAT55 & $\begin{array}{l}\text { The content of the messages } \\
\text { are short, brief, useful and } \\
\text { powerful. }\end{array}$ & 0.92 & 0.87 \\
\hline 3 & SAT54 & $\begin{array}{l}\text { I prefer more frequent mes- } \\
\text { sages from lecturers. }\end{array}$ & 1.23 & 1.17 \\
\hline 4 & USE139 & $\begin{array}{l}\text { You prefer to navigate in 3D } \\
\text { (text, picture, mms, audio and } \\
\text { video). }\end{array}$ & 1.50 & 1.48 \\
\hline 5 & SAT53 & $\begin{array}{l}\text { I'm satisfied with the time } \\
\text { each message delivered to me. }\end{array}$ & 0.82 & 0.80 \\
\hline 6 & USE144 & $\begin{array}{l}\text { You think SMS-Learning is } \\
\text { effective to help your study. }\end{array}$ & 0.74 & 0.73 \\
\hline 7 & USE136 & $\begin{array}{l}\text { It is safe to use the system to } \\
\text { save your learning content. }\end{array}$ & 0.85 & 0.71 \\
\hline 8 & SAT61 & $\begin{array}{l}\text { The messages send to me can } \\
\text { be illustrated in my mind. }\end{array}$ & 1.16 & 1.17 \\
\hline 9 & SAT59 & $\begin{array}{l}\text { The messages send to me } \\
\text { promptly. }\end{array}$ & 0.71 & 0.69 \\
\hline 10 & USE142 & $\begin{array}{l}\text { Only one word or term is used } \\
\text { to describe any item. }\end{array}$ & 1.00 & 1.13 \\
\hline 11 & SAT62 & $\begin{array}{l}\text { The m-learning is more attrac- } \\
\text { tive than the traditional learn- } \\
\text { ing method. }\end{array}$ & 1.00 & 0.90 \\
\hline 12 & USE138 & $\begin{array}{l}\text { It is clear to navigate in 2D } \\
\text { (merely text messaging). }\end{array}$ & 1.11 & 1.42 \\
\hline Shean & SAT58 & $\begin{array}{l}\text { The cost of communicating in } \\
\text { the mobile learning course } \\
\text { dents was acceptable. }\end{array}$ & 1.12 & 1.18 \\
\hline & S.D. & $\mathbf{1 . 0 0}$ & $\mathbf{1 . 0 1}$ \\
\hline & & $\mathbf{0 . 2 1}$ \\
\hline
\end{tabular}

TABLE IV.

INEFFECTUAL ITEMS

\begin{tabular}{|c|c|c|c|c|}
\hline No & Item & Statement & $\begin{array}{c}\text { Infit } \\
\text { MNSQ }\end{array}$ & $\begin{array}{r}\text { Outfit } \\
\text { MNSQ }\end{array}$ \\
\hline 1 & SAT56 & $\begin{array}{l}\text { The fees of the messages } \\
\text { charged of RM0.15 are } \\
\text { reasonable. }\end{array}$ & 1.74 & 1.85 \\
\hline 2 & SAT63 & $\begin{array}{l}\text { The messages sent to me are } \\
\text { disturbing my life. }\end{array}$ & 2.46 & 3.11 \\
\hline 3 & SAT60 & $\begin{array}{l}\text { I wish to receive important } \\
\text { news from school through } \\
\text { messages. }\end{array}$ & 1.83 & 1.92 \\
\hline 4 & SAT57 & $\begin{array}{l}\text { The fees of messages } \\
\text { should be cheaper. }\end{array}$ & 2.32 & 2.14 \\
\hline 5 & USE134 & The system is easy to use. & 0.42 & 0.42 \\
\hline 6 & USE135 & $\begin{array}{l}\text { It is easy to learn by using } \\
\text { the system. }\end{array}$ & 0.59 & 0.58 \\
\hline 7 & USE137 & $\begin{array}{l}\text { The system is effective and } \\
\text { efficient. }\end{array}$ & 0.57 & 0.53 \\
\hline 8 & USE141 & Jargon is avoided. & 0.59 & 0.57 \\
\hline 9 & USE143 & $\begin{array}{l}\text { Terminology is consistent } \\
\text { with general usage. }\end{array}$ & 0.51 & 0.53 \\
\hline
\end{tabular}




\section{Variable Map}

Figure 1 presents a map of the items, ranked by level of satisfaction and system usability, and the respondents, ranked by their willingness to endorse with the items. Within the map, items have been labeled by a key word in the statement. The items and person map display a hierarchy of characteristics preferences as rated by participants and indicates that participant's willingness to endorse the items is generally very high. Items that are located at the top of the map have been identified as those that are most difficulties to endorse [26]. Those at the bottom are easier to endorse; thus as you move from bottom to top of the map, items are more difficult to endorse.

Results suggest the easiest item to endorse is item USE140; The language used is simple enough. It is an interesting result that students endorse the simple language used in SMS-Learning Program as the most satisfied item. By using the simple language in the program, students easily understood the content and the process of transferring information from instructors to the student were simplified. This result was consistent with item SAT55, The content of the messages is short, brief, useful and powerful. It shows that students who are the distance learners are interested to receive a concise message which means the message is brief, short, explicable and very useful in assisting them in revising the subject taken anywhere and anytime. Because of the practicality of the SMS-Learning in term of language used, responses from students shows that they prefer to subscribe to the program as supported by Item 54; I prefer more frequent messages from lecturers. They choose to receive more frequent messages instead of once a day so that they are able to keep updating their knowledge and study continuously.

When there were positive responses to the simplicity of the language used in the program and the frequency of receiving the message, there was a disagreement result which shows the most difficult item to endorse by respondents. It was item SAT58, The cost of communicating in the mobile learning course with the tutor and other students was acceptable. Responses from the survey explained that the cost of communication will be the barrier in SMS-Learning program. This SMS-Learning program is still in the early stage of development, therefore the cost of communications via SMS slightly outnumbers the cost of learning using electronic learning (e-learning). Learning via e-learning was nearly at zero cost and it will encourage the decreasing in SMS cost.

This study also found students agree with item USE139; You prefer to navigate in $3 D$ (text, picture, $\mathrm{mms}$, audio, and video). It explained that most of the respondents own a mobile phone that is able to deliver and receive not just a text message. Respondents show the interest in receiving learning material in form of pictures, sounds and animation in order to enhance their understanding. It was a contrarily result with the item USE138, It clear to navigate in 2D (merely text messaging). Respondents had difficulties in endorsing this item. The possible reason behind this result is that respondents are ready to navigate in $3 \mathrm{D}$ application and they owned the latest mobile phone which comes with many functions instead of text messaging. This result shows that respondents will easily agree if SMS-Learning program provides various type of message in the development of mobile phones.

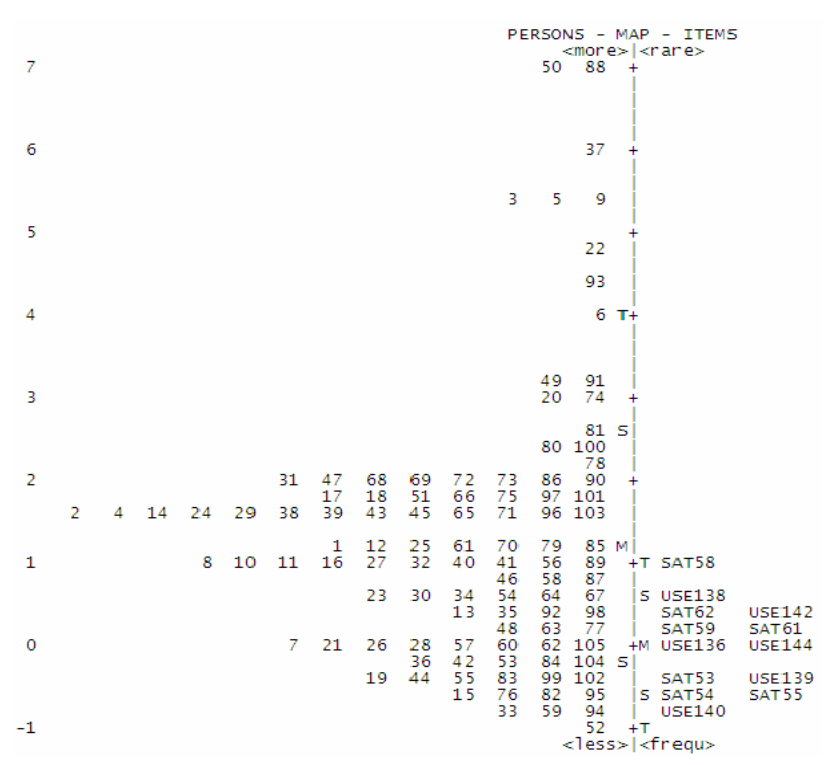

Figure 1. Item/Person map

\section{LIMITATIONS}

The first limitation is the number of participants adopting SMS-Learning was extremely small and this precluded much statistical analysis. Larger samples in this study would have been helpful in overcoming the problem. The study participants were enlist from a single university and utilized students from School of Distance Education only. Therefore, the wide-ranging of the study could be limited to the institutions of similar size and courses. At the early stage of study, there was only one-way interaction between instructors and students and it showed a lack of interactive communication between students and instructors. In the future, researchers may implement two way interactions to create an interactive way of learning.

\section{CONCLUSION}

This study has developed and investigated SMSLearning program and it showed that the majority of the respondents accepted the SMS-Learning program as a tool of teaching with the language used in this program. It showed that the simplistic is the constituent of mobile learning. The instructors have to ensure that the language used must be short, brief, useful and powerful to help them in their study. Through Rasch results, student's willingness to endorse items and the corresponding items are clearly stated and compared along one scale as they were analyzed and evaluated. The survey instrument is reliable and is able to separate both the sample of students and items. This study provides improvement suggestions to this SMS-Learning program. With the additional capability of mobile phone, SMS-Learning has the potential to become one of the most interactive learning tools in this era. As this occurs, additional studies should take place and more students will have the opportunity to engage in SMS-Learning program which will list more offered subjects.

\section{ACKNOWLEDGMENT}

The authors would like to acknowledge Universiti Sains Malaysia for the support under RU grant and USM Fellowship scheme. 


\section{REFERENCES}

[1] Georgiev, T., Georgieva, E., \& Smikarov, A. (2004). M-LearningA new stage of e-learning. Paper presented at the International Conference on Computer Systems and Technologies.

[2] Kim, S.H., Mims, C. \& Holmes, K.P. (2006). An Introduction to Current Trends and Benefits of Mobile Wireless Technology Use in Higher Education. AACE Journal, 14(1), 77-100. Chesapeake, VA: AACE.

[3] Sharples, M., Taylor, J., \& Vavoula, G. (2005). Towards a theory of mobile learning. Paper presented at mLearn 2005, Capetown South Africa. http://www.mlearn.org.za/CD/papers/SharplesTheory of Mobile.pdf

[4] Maginnis, F., White, R., \& Mckenna, C. (2000, November/December). Customers on the move: m-Commerce demands a business object broker approach to EAI. eAI Journal, 58-62.

[5] Goodison, T. A. (2001) The implementation of m-learning in UK higher education. Proceedings of ED-MEDIA 2001. AACE Press, 25-30 June 2001, Tampere, Finland, pp.613-618

[6] MCMC (2009). Fact \& Figures (Statistics \& Record). Retrieved September 11, 2009 form http://www.skmm.gov.my/facts_figures/ stats/index.asp

[7] Gilligan, R. and Heinzmann, P. 2004. "Exploring how cultural factors could potentially influence ICT use: An Analysis of European SMS and MMS use", Cultural Difference Workgroup COST 269

[8] Harris, P., Rettie, R. and Cheung, C.C. 2005. "Adoption and usage of m-commerce: A cross-cultural comparison of Hong Kong and the United Kingdom", Journal of Electronic Commerce Research, 6(3), 210-224

[9] Peersman, G and Cvetkovic, S (2000). The Global System for Mobile Communication Short Message Services. IEEE Personal Communications, June 2000. The University of Sheffield.

[10] Hard af Segerstad, Y. (2005). Language use in Swedish mobile text messaging. In R. Ling \& P. E. Pedersen (Eds.), Mobile Communications: Re-negotiation of the Social Sphere (pp. 313-333). London: Springer-Verlag.

[11] Trifonova, A. (2003). Mobile learning-review of the literature. (Technology Report No. DIT-03-009). University of Trento, Department of Information and Communication Technology.

[12] Ling, R., \& Sollund, A. (2002). Final Report for. Youngster Project, EU IST Program. Roessler, P. and Hoeflich, J, pp, 133-157.

[13] Wang, Y. (2003). Assessment of learner satisfaction with asynchronous electronic learning systems. Information \& Management, 41, 75-86. doi:10.1016/S0378-7206(03)00028-4.

[14] Shee, D. Y., \& Wang, Y. (2008). Multi-criteria evaluation of the web-based e-learning system: A methodology based on learner satisfaction and its applications. Computers \& Education, 50, 894905. doi:10.1016/j.compedu.2006.09.005.

[15] Lindgaard, G., \& Dudek, C. (2003). What is this evasive beast we call user satisfaction. Interacting with Computers, 15(3), 429-452. doi:10.1016/S0953-5438(02)00063-2

[16] Sun, P., Tsai, R. J., Finger, G., Chen, Y., \& Yeh, D. (2008). What drives a successful e-Learning? An empirical investigation of the critical factors in uencing learner satisfaction. Computers \& Education, 50, 1183-1202. doi:10.1016/j.compedu.2006.11.007.

[17] Flavia 'n, C., Guinalı 'u,M., \& Gurrea, R. (2006). The role played by perceived usability, satisfaction and consumer trust on website loyalty. Information and Management. The International Journal of Information Systems Applications, 43(1), 1-14.

[18] Nielsen, J. (1994). Usability engineering. San Francisco: Morgan Kaufman.

[19] Nielsen, J. (2005) Usability 101. Retrieved August 14, 2009, from http://www.useit.com/alertbox/20030825.html

[20] Linacre, J.M. (2009). A User's Guide to Winsteps Rasch Model Computer Programs. Chicago,IL: MESA Press.

[21] Ren, W., Bradley, K.D., Lumpp J.K. (2008). Applying the Rasch Model to Evaluate an Implementation of the Kentucy Electronics Educations Education Project. Journal of Science Education and Technology, 17(6), 618-625. doi:10.1007/s10956-008-9132-4

[22] Winsteps Help (2007) Logit and probit: what are they? Retrieved August 17, 2009, from http://www.winsteps.com/winman/ whatisalogit.htm

[23] Smith, R. M. (1996). Polytomous mean-square statistics. Rasch Measurement Transactions, 6, 516-517.

[24] Fox, C. (1999). An introduction to the partial credit model for developing nursing assessments. Journal of Nursing Education, 38(8), 340-346.

[25] Sekaran, U. (2000). Research Methods for Business: A Skill Building Approach. Singapore: John Wiley \& Sons Inc

[26] Harris, Jr. (2006). A study of Black University Students' Perception of Marriage. Constructing and Evaluating measures: Applications of the Rasch measurement Model. Symposium presented at the Mid-Western educational Research Associationannual meeting, Columbus, OH, pp.19-24

\section{AUTHORS}

Issham Ismail is with the School of Distance Education, Universiti Sains Malaysia, Minden, Pulau Pinang, 11800 Malaysia (e-mail: issham@usm.my)

Rozhan M. Idrus is with the School of Distance Education, Universiti Sains Malaysia, Minden, Pulau Pinang, 11800 Malaysia. He is specialized in Open and Distance Learning Interactive Technologies and e-Learning (e-mail: rozhan@usm.my).

Hanysah Baharum is a student in the School of Distance Education, Universiti Sains Malaysia, Minden, Pulau Pinang, 11800 Malaysia and currently doing her master in Educational Technology in Universiti Sains Malaysia. (e-mail: hanysahbaharum@gmail.com).

This work was supported in part by the Universiti Sains Malaysia under RU Grant 1001/PJJAUH/817015

Manuscript received December $3^{\text {rd }}, 2009$. Published as resubmitted by the authors on June $29^{\text {th }}, 2009$. 